\title{
Framework for Teaching the Design and Innovation of Green IT Services for High Social Impact
}

\author{
César R. Cárdenas ${ }^{1}$, Rodrigo Mata ${ }^{2}$ \\ ${ }^{1}$ Tecnológico de Monterrey, Campus Querétaro \\ ${ }^{2}$ Universidad Tecnológica de Querétaro \\ 1'ccardena@itesm.mx, ${ }^{2}$ rmata@uteq.edu.mx
}

\begin{abstract}
This paper proposes a framework for projects of academic programs related to information and communications technologies. The framework is intended to include sustainability issues, innovation and high social impact. It integrates four domains of practical knowledge: the practices of green information technologies, the framework in information systems research, the guide to the software engineering body of knowledge, the body of knowledge for project management and principles.
\end{abstract}

Keywords: Green IT, IT Service Innovation, Socially Relevant Computing, Service-Learning in Information Systems.

\section{Introduction}

To achieve environmental sustainability we need to involve many actors. We must join industrial and academic intentions that contribute to the preservation of the environment and thus contribute to the global needs such as those presented by the Development Program of the United Nations (UNDP) which proposes challenges to everyone in order to generate new technological innovations for 2015 and post-2015. The MDGs (The Millennium Development Goals) have to be considered as well. The MDGs provide a framework for the entire international community to work together towards common goals. According to UNDP, environmental sustainability is vital to avoid reaching the point of no return. The ten most important environmental problems facing the planet are: population, climate change, biodiversity loss, nitrogen and phosphorus cycles, water, ocean acidification, pollution, wear, ozone, overfishing and deforestation [1]. Meanwhile, Mexico faces serious problems such as deforestation, declining freshwater bodies, forestry, hunting of protected areas and inadequate waste management [2]. The environmental problems in Mexico can be divided into five areas: rural development, natural resources and biodiversity, urban development, industrial growth, regulatory and institutional development and education [3]. The Information and Communications Technologies (ICTs) specialized academic programs can also contribute to preserving the environment and saving energy. This research seeks to propose a solution from the ICT's specialized educational system, where for instance, academic-industry projects and final projects are very valuable as experiential experiences, however they still relatively simple. Some of the results 
from these projects have little innovation, sustainability and high social impact issues considered. Also, few academic projects supporting sustainability and environmental care are not really implemented and do not promote research and entrepreneurship. We believe that the low or no participation of students in innovative projects supporting green initiatives and social impact is due to, for example, the lack of initiatives involving these concepts as an opportunity to address problems and include them in their learning objectives. Also, no resources are allocated; no actions or initiatives in the universities are implemented. One way to motivate students are the competitions held in the country, for instance, the Cleantech Challenge Mexico [4], the most important competition of green companies in the country, or the global competition Cleanweb Hackathon [5], which consist on demonstrating the impact of the application of IT in energy and resources and aimed at creating web and mobile applications that solve energy and sustainability problems. Unfortunately the universities participation is very low, students who enroll have good ideas but lack in realizing the business of the idea and many have trouble to make well-founded technical proposals based on a methodology for projects development ${ }^{1}$.

To our knowledge, few universities in Mexico are including activities in their educational processes to promote and encourage environmental awareness and promote through research projects a harmonious relationship between the environment and human activities in order to ensure sustainability. For the Tecnológico de Monoterrey (a.k.a. ITESM), sustainable development skills are promoted through the curriculum. This program prepares teachers to include in each of their courses activities related to sustainable development from the discipline [6]. Another example is the Universidad Tecnológica de Querétaro who promotes sustainable development in two ways, providing a university environment to well prepare graduates to become agents of change towards sustainable development in our society under the vision of being recognized as the Sustainable University [7].

An opportunity area that contributes to the lack of innovation and the generation of green projects and social impact is the lack of research and development in the higher education field and the lack of use of industry-based frameworks grounded in the bodies of knowledge and based in environmental sustainability, in innovation and social problems. By including this, it will allow the implementation of projects to abate problems systematically and appropriately, following standards and design processes based on knowledge and fundamentals. In educating IT engineers, a solution to the issues raised can be based on Green IT, a holistic approach to the environment and the sustainable management of IT activities. It can also be complemented with other educational paradigms aiming to find solutions to social problems and environmental care as well as new educational paradigms focused on finding solutions based on science and human behavior to make it possible to design innovative devices that can help sustainability. From all the above reasons we conclude that a framework for academic projects is needed so the students can learn it and develop artifacts that meet sustainability requirements.

\footnotetext{
${ }^{1}$ Personal experience. The authors have been judges of the event Cleantech Challenge Mexico in the center zone of the country.
} 
In this paper we propose a framework for projects of academic programs related to ICTs. The framework is intended to include sustainability issues, innovation and high social impact. It integrates four domains of practical knowledge and is aimed at creating innovative artifacts. In section 2, the environmental impact of IT development is presented. Section 3 presents new paradigms in engineering education. In section 4 we present the state of the art in Green IT teaching. Section 5 presents frameworks and bodies of knowledge that we consider relevant to this research effort. Section 6 presents the research methodology used in this research. Section 7 presents a first approach to our proposal, finally in section 8 we provide the conclusions and future work.

\section{Environmental Impact of the Information Technology Sector}

The technology sector is a large energy consumer with a significant carbon footprint. $1 \%$ of global electricity consumption is concentrated in data centers around the world and Google accounts for $0.01 \%$ of global electricity consumption [8]. CO2 emissions across the technology sector are equivalent to $2 \%$ of global emissions [8]. This information shows that ICT should contribute to reducing electricity consumption and $\mathrm{CO} 2$ emissions to the atmosphere. In the education sector, we should intervene so that future IT engineers will bet for the efficient use of computer hardware. The efforts known as Green Computing and Green IT ask the technology to be sustainable and energy efficient. Green IT is a technological initiative for the efficient use of computing resources, it seeks to minimize environmental impact, maximize their economic viability and meet social norms. Green IT is perceived as a theoretical term, distant and difficult to implement in everyday processes, in Information Systems (IS) and ICT barely appears in the consolidation of data centers and reducing the number of physical servers and virtual concepts of Cloud Computing. But it must be driven from a culture of education in universities offering these specialties. This will reduce environmental problems through the implementation of green technologies in government and private initiatives.

\section{Paradigms of Engineering Education}

Besides Green IT, there are other educational paradigms aimed at finding solutions for environmental care. For example the paradigm Sustainable Engineering [9], which is applied to the principles of engineering and design, and promote social and economic development by minimizing environmental impact through energy savings and the redesign and readjustment of existing systems. Service Learning is a learning model based on service; it combines community service with classroom instruction, focusing on critical and reflective thinking, and personal and civic responsibility [10]. Socially Relevant Computing (SCR) is a computing paradigm that focuses on the use of computation to solve problems that students are passionate. It presents computer science as a support discipline that solves problems that are socially relevant [11]. Citizen Engineer is another paradigm that seeks the connection point between science 
and society, between pure knowledge and how it is used. Citizens Engineers are responsible and promote technological processes and products that are environmentally, economically and socially responsible participants [12]. The first author of this paper has developed frameworks of technological innovation for high social impact [13-14].

\section{Teaching Green IT Engineering}

The Green IT concept has been subject of study for the universities. In [15], authors study Green IT, examined the position taken by IT departments at some universities regarding environmental sustainability and how the work they do helps to be more responsible with the environment in their business, teaching and research activities. The study concludes that higher education is not taking an active role and most institutions take sustainability efforts more opportunistic than systemically. In [16], authors discuss the main research challenges and solutions development, education and training activities about Green IT, safe computing and telecommunications. One of the objectives of their work is to discuss the Green IT paradigm to analyze the modern trends in the fields of research, development and security education related to security and low energy consumption. They conclude that ICTs consume relatively little power, but the use is expanding more and Green IT paradigm is implemented in various areas. Other researchers report that due to the rapid increase in the use of ICTs worldwide, they have become an important subject of research. However, recycling end of life ICT products is becoming an environmental issue that should concern all and consider that stakeholders at all levels, including universities, must increase the awareness of students, especially in relation to their moral responsibility to contribute to sustainable development, and guide them to a better and more sustainable future [17]. To our knowledge, there is no previous work that focuses on the contribution of this paper which is a framework that promotes sustainable thinking processes in students.

\section{Frameworks and Bodies of Knowledge}

Based on all the above and to provide a solution to the problem stated previously, we propose the integration of industry recognized frameworks and bodies of knowledge. The Design Science in Information Systems Research Model [18], which aims to describe the performance of research in the science of information systems through a conceptual framework. In this model, the paradigm of design science, knowledge and understanding of a problem and its solution are realized with the construction and implementation of a designed artifact. Hevner [19] elaborates his model based on two paradigms that characterize research in information systems, behavioral science and design science. In this paper, we extend the previous work by integrating three more frameworks. The Green IT approach, the Guide to the Software Engineering Body of Knowledge (SWEBOK) provides a basis in the field of software engineering. It serves as a dynamic compendium, develops and evolves as software engineering matures. 
The current version was developed and created by leaders in the field. It is revised and updated frequently in order to adapt to changes [20]. The Project Management Body of Knowledge (PMBOK) describes the sum of knowledge involved in the profession of project management. Provides common terminology and is defined as guide to the project management, published by the PMI (Project Management Institute), constitutes the sum of knowledge of the professionals, brings together innovative and professional practices, proven and accepted, skills, techniques and tools. PMBOK describes methods and practices for the life cycle of a project. The application of these practices can lead to project management and maintain greater control, allowing make effective and efficient projects (scope, time, cost), as well as ensure quality throughout the life of project [21].

\section{Methodology}

For this work, documentary research was performed; the theme was selected to investigate from the perspective of sustainability issues in Mexico and how to solve this problem with the support of the academic processes and their students. Exploratory work was conducted on the practices carried out in the Higher Education Institutions (HEIs), specifically in the ICT education, about the production of ecological social impact academic projects, gathering information on the subject was held in looking for ideas, data and researches presented in the past to have a solid basis for improving our understanding. After, literature and publications were reviewed looking for other jobs with schemes and paradigms about Green IT and Innovation in HEIs. We did not find documents or research that considers the perspective from frameworks. Then, we develop the themes and study objectives were defined. Then an index was designed to develop and complete the first phase of this research process. Finally the content was developed and organized. Ultimately the final work and conclusions of the first phase of this research were written.

\section{Results: Green Social Innovation IS Framework}

Through the integration of the framework Design Science in Information Systems Research and bodies of knowledge, SWEBOK, PMBOK, Green IT, and educational paradigms. We concluded with our particular design, Green Social Innovation IS Framework. This effort is a proposal to teach the design of ICT services with a green innovative approach and high social impact. This work is founded on the life cycle of an IT project, the steps, since it begins with the need for a system until it is replaced. According to the SWEBOK guide [20], steps are usually made with the phases of requirements, design, construction, testing and maintenance. The software life cycle and its stages are in the recent guide, so we suggest use this SWEBOK as a basis for the development of each phase of project development considered; like the SWEBOK, PMBOK allows the stages of a project can be aligned with the software life cycle and practices and knowledge described on this guide, can be adapted to any software project. Given the proper review of the two bodies of knowledge PMBOK 
and SWEBOK, which are the basis on this initial approach to the development of software projects. The initial step of the framework, requirements analysis, should be initiated oriented from an approach based on the exploration of the social needs of the environment, in which can benefit a large percentage of the population in order to be considered as a high social impact project. After, we suggest that exploring and using the educational paradigms address analysis, looking for the positive impact on the environment and society. For all next steps, it is considered as the basis of knowledge SWEBOK and PMBOK, particularly looking for implement in each phase of the project the principles and practices of Green IT to generate artifacts that will support sustainability.

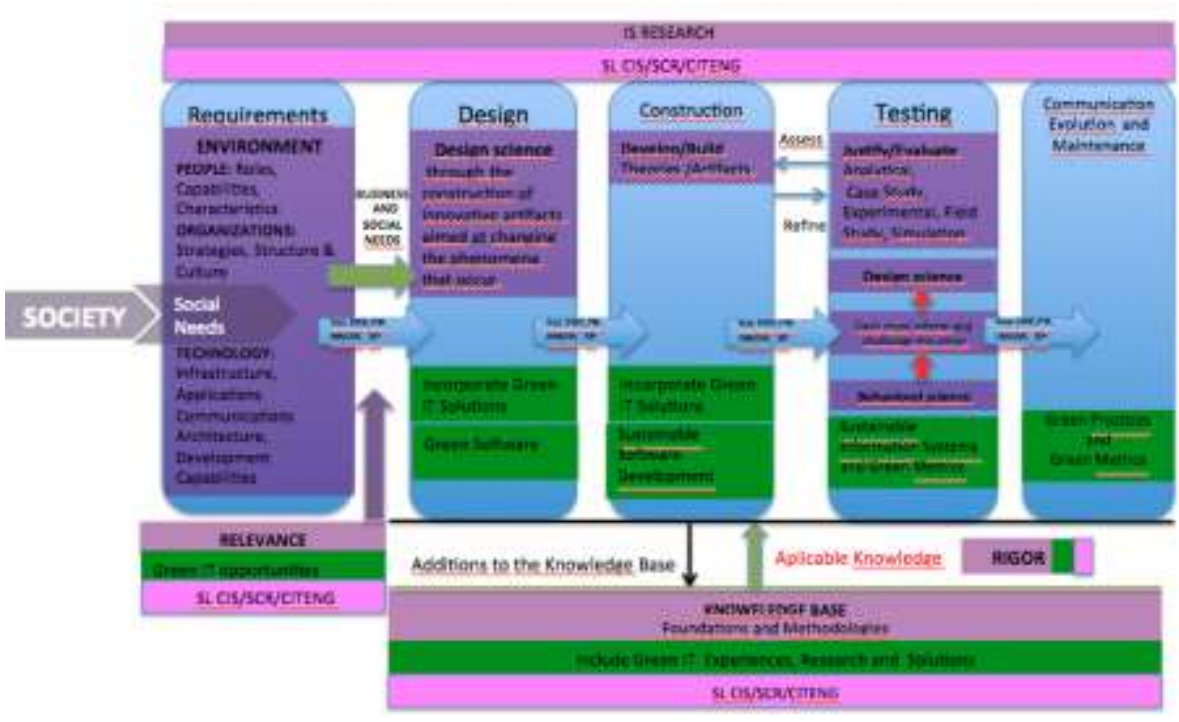

Figure 1. Green Social Innovation IS Framework.

In figure 1, the proposed framework is shown. In the first stage of requirements referring to the environment, which is where problems of interest and opportunities resides, in our approach we propose open the system and bring it to the social needs of the environment where these are manifested and can be resolved through a draft IS Research. Social needs should be assessed in the context of the prevailing needs of the social system, considering the culture and existing social processes. These factors are also positioned relative to the existing ITs structures, applications, communication architectures and development capabilities. Which together define the needs of a society or part of it to be identified or sought by the student. Focusing on research activities, in the pursuit of social problems and address the needs that are identified, the relevance of the work research and social impact is assured. Once a need is identified, research is carried out in two complementary phases. Behavioral science research focused through the development and justification of theories that explain or predict related to the identification of social needs phenomena. Basic skills with which the student must have, are the foundations of the SWEBOK, PMBOK, SDLC and principles and practices of Green IT, these provide guidelines for justification and 
evaluation phase of the project and helps to justify the Rigor and Relevance, which are key factors to achieve innovative, green and high social impact projects. The Rigor between the body of knowledge and the phases of design, construction, testing and maintenance is achieved by appropriately applying known methodologies and fundamentals to generate new knowledge. New contributions to the foundations and research methodologies in the IS projects will be evaluated according to how the they help the social needs what students found in an appropriate environment, and how the artifacts are used, and also, how new knowledge is added to the knowledge base through research and practice developed. The rigor of the framework should be applied to actually build new knowledge and to enrich the knowledge base. To actually generate innovation, is essential establishing the differentiation between routine design and construction of the research design. The difference is in the nature of the problem and its solution, routine design is the application of existing knowledge to social problems using known artifacts of best practices in the knowledge base (which is commonly done at universities). The research design science (innovative, green and high social impact) addresses important unsolved problems, solutions uniquely innovative or troubleshooting more effective or efficient solutions. The objective of the proposed framework is to generate artifacts green, innovative for high social impact and the acquiring new knowledge and understanding to enable the development and implementation of technology-based solutions that solve important social problems that so far have not been resolved.

\section{Conclusions and Future Work}

SWEBOK, PMBOK, Green IT and the paradigms in education and engineering are useful to solve independently problems and propose social initiatives and sustainability. In this way its usefulness is limited in the specific area, therefore they just help a little to teachers and students to find areas of opportunity in social and sustainability issues facing the global village, or problems that can be solved with green technologies. With the integration of the Design Science in Information Systems Research Model, as well as, the basis of the bodies of knowledge, PMBOK and SWEBOK and also the integration of the paradigms in education and principles and practices of Green IT, is possible to develop projects that are useful and have a strong involvement in social issues and sustainability. Applying this integration in academic research projects may get green, innovative product with high social impact. Overall for the framework presented its usefulness and effectiveness must be evaluated and measured to make suggestions on its implementation and deployment. Future goals are, evaluate courses and academic plans that can integrate the framework.

\section{References}

1 Planet Earth Herald, http://planetearthherald.com/top-10-environmental-issues

2 Ochoa, G.: Hiperactivos. http://www.hiperactivos.com/ambientales.shtml 
3 Gutierréz, B., \& Herrera, N. I.: La Ingeniería Ambiental en México. Publicaciones Anuies, $\mathrm{http} / / /$ publicaciones.anuies.mx/acervo/revsup/res111/txt4_2.htm (2010)

4 Cleantech Challenge México 2014, http://www.cleantechchallenge.org

5 Cleanweb Hackathon, http://www.cleanwebhackathon.com

6 Tecnológico de Monterrey.: SNC Portal Informativo, $\mathrm{http} / /$ www.itesm.mx/wps/wcm/connect/snc/portal+informativo

7 Universidad Tecnológica de Querétaro. UTEQ Visión, http://www.uteq.edu.mx/test/ConoceLaUTEQ/MisionVisionObjetivos.php

8 Velasco, J.: Centros de datos sostenibles, optimizando la refrigeración de los servidores Think Big. Tecnología, http://blogthinkbig.com/cat/tecnologia (2013)

9 WiseGEEK.: Clear answers for common cuestions, http://www.wisegeek.com

10 American Association of Community Colleges.: aacc.nche.edu. $\mathrm{http} / / /$ www.aacc.nche.edu/Resources/aaccprograms/horizons/Pages/ (2014). June 14th, 2014.

11 Socially Relevant Computing.: src.cse.buffalo. http://src.cse.buffalo.edu (2009). June 19th, 2014.

12 Douglas; Papadopoulos; y Boutelles.: Citizen Engineer: A Handbook for Socially Responsible Engineering. P. Education. (2009)

13 Cárdenas, C., "A Multidisciplinary Approach to Teach the Design of Socially Relevant Computing Systems for Social Change," International Journal of Engineering Education. Special Issue on Methods and Cases in Computing Education. ISSN-e 0949-149X, Vol. 27, no. 1, 2011, págs. 3-13.

14 Cárdenas, C.; Moysen, R., Palma, D., Loya, E.,; Signoret, C., "A Multidisciplinary Course based on Social Intelligence Design and Collaborative Learning," International Journal AI \& Society, Special Issue on SID 2008, Springer Verlag.

15 Sheehan, M.: Powering Down Green IT in Higher Education. EDUCAUSE Center for Analysis and Research. Research and publications. http://www.educause.edu (2010)

16 Kharchenko, V., Gorbenko, A., Sklyar , V., \& Phillips, C.: Green Computing and Communications in Critical Application Domains: Challenges and Solutions. IEEExplore. Digital Library, http://ieeexplore.ieee.org (2013)

17 Issa, T., Issa, T., \& Chang, V.: Sustainability and green IT education: Practice for incorporating in the Australian higher education curriculum, Curtin University. Library Curtin University, http://espace.library.curtin.edu.au/ (2014)

18 Hevner, A. R.; March, S. T.; Park, J.; \& Ram, S.: Design Science in Information Systems Research. MisQuarterly, http://misq.org/design-science-in-information-systemsresearch.html (2004)

19 Hevner, A.; Chatterjee, S.: Design Research in Information Systems Theory and Practice. Springer. (2010)

20 IEEE Computer Society. Pierre B.; Fairley R.: Guide to the Software Engineering Body of Knowledge SWEBOK Vol. 3.0. IEEE. (2014)

21 PMI, Project Management Institute. PMBOK Guide and Standards, http://www.pmi.org/PMBOK-Guide-and-Standards.aspx (2014) 